\title{
O modelo de tratamento das comunidades terapêuticas: práticas confessionais na conformação dos sujeitos
}

\section{The treatment model of therapeutic communities: confessional practices in shaping subjects}

\section{El modelo de tratamiento de las comunidades terapéuticas: las prácticas religiosas en la conformación de los sujetos}

\author{
Luciana Barcellos Fossi* \\ Universidade Federal do Rio Grande do Sul - UFRGS, Porto Alegre, Rio Grande do \\ Sul, Brasil
}

\author{
Neuza Maria de Fátima Guareschi** \\ Universidade Federal do Rio Grande do Sul - UFRGS, Porto Alegre, Rio Grande do \\ Sul, Brasil
}

\begin{abstract}
RESUMO
Este artigo aborda a especificidade do tratamento nas comunidades terapêuticas bem como seus efeitos na produção dos sujeitos usuários de substâncias psicoativas através da análise de projetos de tratamento de quatro comunidades terapêuticas, disponíveis na internet. A partir do Plano Integrado de Enfretamento ao Crack, publicado pelo governo federal em 2010, a política pública para drogas no Brasil incluiu o tratamento em comunidades terapêuticas, através de financiamento público, como uma estratégia de cuidado para os usuários de álcool e outras drogas. Assim, apresentamos a estrutura e o funcionamento dessas instituições bem como seu modelo de tratamento para os usuários de drogas, baseado na metodologia dos doze passos dos Alcoólicos Anônimos. Apontamos, dessa forma, as práticas de confissão no tratamento para usuários de drogas, como a articulação entre a moral religiosa e as tecnologias de disciplina e a biopolítica na conformação do modelo de atenção à saúde nesse contexto.

Palavras-chave: comunidade terapêutica, drogas, biopolítica.
\end{abstract}

\section{ABSTRACT}

This article discusses the specificity of treatment in therapeutic community licensed under the Single Health System as well as their effects on the production of the subject drug users through the design analysis of four therapeutic treatment available on the internet community. From the Integrated Plan to Combat Crack, published by the federal government in 2010, public drug policy in Brazil included treatment in therapeutic communities, through public funding as a strategy of care to users of alcohol and other drugs. Thus, we present the structure and functioning of these institutions as well as the treatment model for drug users, based on the 
methodology of the twelve steps of Alcoholics Anonymous. We point out in this way, the practice of confession in the treatment for drug users, and the link between the religious and moral technologies of discipline and biopolitics shaping the health care model in this context.

Keywords: therapeutic community, drug, biopolitics.

\section{RESÚMEN}

En este artículo se analiza la especificidad del tratamiento en las comunidades terapéuticas con licencia bajo el Sistema Único de Salud, así como sus efectos sobre la producción de los consumidores de drogas sometidos a través del análisis de diseño de cuatro tratamientos terapéuticos disponibles en la comunidad de Internet. Desde el Plan Integral de Lucha contra la grieta, publicado por el gobierno federal en 2010, la política pública de medicamentos en Brasil incluyó un tratamiento en las comunidades terapéuticas, a través de la financiación pública como una estrategia de atención a los usuarios de alcohol y otras drogas. De este modo, se presenta la estructura y el funcionamiento de estas instituciones, así como el modelo de tratamiento para usuarios de drogas, basado en la metodología de los doce pasos de Alcohólicos Anónimos. Destacamos de esta manera, la práctica de la confesión en el tratamiento de usuarios de drogas, y el vínculo entre las tecnologías religiosas y morales de la disciplina y la biopolítica que configuran el modelo de atención de la salud en este contexto.

Palabras clave: comunidad terapéutica, droga, biopolítica.

\section{Introdução}

Nas últimas décadas, a questão do uso de drogas vem ocupando lugar significativo na mídia, nas políticas de Estado, nos planos de governo e no cotidiano dos trabalhadores e dos serviços de saúde mental. A partir de 2010, o governo federal passou a investir fortemente na questão das drogas, propondo novas estratégias e reforçando outras já existentes, bem como incrementando o orçamento para as ações propostas a fim de solucionar o 'problema' ou, pelo menos, minimizá-lo. Dentre as propostas, está a ampliação dos serviços de atenção à saúde para os usuários de drogas, trazendo para rede serviços que inicialmente não faziam parte dela. As comunidades terapêuticas, serviços de internação na modalidade de moradia para usuários drogas, passaram a compor a rede de saúde pública através do financiamento estatal.

Dentre os serviços previstos para usuários de substâncias psicoativas, as comunidades terapêuticas não faziam parte da rede de atenção à saúde, já que não eram consideradas serviços de saúde. Sua regulamentação para funcionar como instituição de tratamento de usuários de drogas se dá pela Agência Nacional de Vigilância Sanitária, através da Resolução - RDC no 101 (2001). Entretanto, seu conveniamento com o Sistema Único de Saúde (SUS) como serviço de atenção da rede pública acontece a partir de 2011. As comunidades terapêuticas são instituições privadas e, muitas vezes, 
de caráter confessional, em que a religião é imposta como a principal estratégia de tratamento, independentemente das conviç̧ões religiosas do indivíduo anteriores ao ingresso nela. Elas possuem um programa específico de tratamento, que dura de seis a doze meses, conforme a instituição, regras rígidas e atividades obrigatórias, que devem ser seguidas por todos que ingressam na instituição. As visitas dos familiares são parcas e restritas e o contato com o mundo externo é inexistente, inclusive, no que diz respeito às atividades escolares e profissionais.

\section{A política pública para drogas no Brasil: saúde e segurança no campo de atenção ao usuário de drogas}

A política de enfrentamento às drogas no Brasil enseja, em suas proposições, uma luta entre as lógicas de segurança pública e de saúde pública expressas no embate entre as duas políticas instituídas pelo governo brasileiro, a saber: a Política Nacional Antidrogas regulamentada em 2003 pela Secretaria Nacional Antidrogas (estrutura criada pela medida provisória no 1689 (1998) no governo de Fernando Henrique Cardoso e modificada para "Secretaria Nacional de Políticas Sobre Drogas" no governo Lula) e a Política de Atenção Integral ao Usuário de Álcool e Drogas do Ministério da Saúde instituída em 2004 (Garcia, Leal, \& Abreu, 2008).

A política de segurança pública segue a lógica do proibicionismo, seguindo o caminho oposto à tentativa de construção do SUS e da Reforma Psiquiátrica, em que o cuidado à saúde não deveria estar atravessado pela compreensão moralizante do uso de drogas. A lógica do tratamento para usuários de drogas na política pública de saúde, conforme o documento de 2004, estaria pautado pela Redução de Danos, que não prioriza, necessariamente, a abstinência. Existe, portanto, um embate entre os gestores e trabalhadores da saúde, implicados com o cuidado na lógica da Redução de Danos e na defesa do SUS devido ao caráter proibicionista do tratamento que é adotado pelas comunidades terapêuticas.

A inserção da comunidade terapêutica na rede de cuidados está, diretamente, ligada à política de segurança já que é através de um edital da Secretária Nacional de Políticas sobre Drogas (SENAD), vinculado ao Ministério da Justiça, que elas passaram a ser conveniadas. Contudo, estas comunidades terapêuticas, antes mesmo de seu conveniamento, já funcionavam contando com os saberes e as práticas das disciplinas "psi" aliados à lógica religiosa de moralização dos sujeitos.

O exercício de poder gerado no embate entre forças democráticas e forças totalitárias resultou em um jogo de contradições entre a Constituição Brasileira e o Código Penal: a primeira garantindo o 
direito a liberdades individuais e o segundo proibindo que as pessoas usem certas substâncias. Tal contradição remete à conciliação sinistra entre democracia e totalitarismo sobre o eixo das drogas (Passos \& Souza, 2011).

Uma problematização necessária no âmbito das políticas públicas diz respeito ao fato de que tanto o Ministério da Saúde quanto o Ministério da Justiça incidem sobre a temática, mas, em princípio, em perspectivas diferentes. Se de um lado, o Ministério da Saúde indicava a Redução de Danos como diretriz para a política de álcool e outras drogas, por outro, o Ministério da Justiça, através da SENAD prioriza a internação, inclusive a de longa duração, em comunidades terapêuticas, em uma perspectiva de abstinência. No entanto, a verba que financia os leitos nas comunidades terapêuticas é advinda do Ministério da Saúde, que deveria legislar, justamente, no sentido oposto do que está colocado pela SENAD, por preconizar a Redução de Danos como diretriz para o tratamento. A partir do Decreto 7179 (2010) e do edital de conveniamento das comunidades terapêuticas subsequente ao decreto, SENAD e Ministério da Saúde se articulam na operacionalização da política de drogas.

O governo do país a partir de 2011 tem como plano governamental o 'enfrentamento ao crack', sob a campanha "Crack, é possível vencer", com significativo investimento financeiro para contemplar a demanda da sociedade por alguma medida para dar conta de tal problemática. Antes disso, em 2010, foi publicado o Plano Integrado de Enfrentamento ao Crack que conveniou formalmente as comunidades terapêuticas com o SUS (Decreto 7179 - intitulado de "Plano Integrado de Enfrentamento ao Crack e outras Drogas"). Este plano teve como principal e primeira ação imediata a ampliação de leitos para tratamento de usuários de crack. Após esta publicação, foi lançado o Edital 001/2010 do Comitê Gestor do Plano Integrado de Enfrentamento ao Crack e outras drogas, SENAD e Ministério da Saúde para a contratação de leitos em comunidades terapêuticas.

No final de 2011, o governo federal anunciou o investimento de $R \$ 4$ bilhões em ações para enfrentar o crack, prevendo a criação de mais 2.462 leitos para internação de usuários de drogas e a abertura de 2.500 vagas em comunidades terapêuticas. O plano contou, ainda, com uma capacitação intitulada "Fé na Recuperação", para lideranças religiosas através de curso promovido pela SENAD. Portanto, estabelece formalmente 0 papel das instituições religiosas na execução da política nacional proposta pela SENAD.

Com isso, faz-se importante compreender qual a proposta de tratamento das comunidades terapêuticas, sua estrutura e seu funcionamento, para que seja possível problematizar a inserção destas instituições como um serviço da rede pública de atenção aos usuários de substâncias psicoativas. 


\section{Estrutura e funcionamento das comunidades terapêuticas}

A modalidade de tratamento em comunidade terapêutica surgiu na Grã-Bretanha na década de 1940. Inicialmente, foi utilizada para atenção a pessoas com problemas psiquiátricos crônicos a partir da experiência com militares que haviam retornado da guerra com problemas, predominantemente, psicológicos, que eram tratados por psiquiatras em alas especiais de hospitais gerais. $\mathrm{O}$ objetivo era que os pacientes doentes pudessem conhecer melhor sobre seu diagnóstico através de uma aprendizagem social como processo de interação entre equipe médica e pacientes. Para isso, eram realizadas reuniões diárias com todo o grupo de pacientes internados e equipe responsável (Jones, 1972).

Muitas comunidades terapêuticas para tratamento de usuários de substâncias psicoativas seguem o modelo de tratamento preconizado pelo Alcoólicos Anônimos (AA). O AA surgiu em 1935 nos Estados Unidos, fundada por Bill W. (corretor da bolsa de valores de Nova Iorque) e Dr. Bob (médico cirurgião), é uma organização composta, exclusivamente, por ex-bebedores. O método do AA está fundamentado em Doze Passos e Doze Tradições, que, embora inalteráveis, prestam-se a reinterpretações. O programa é baseado na abstinência completa e o eixo básico do tratamento é o intercâmbio da experiência etílica dos alcoolistas (Musumeci, 1994).

Apesar das inúmeras menções à Deus e ao Poder Superior, a Irmandade dos Alcoólicos Anônimos afirma que eles não estão ligados a nenhuma seita ou religião (Revista Vivência, 2011). No entanto, muitas reuniões de grupos de $A A$ acontecem nas dependências de instituições religiosas e confessionais de diversas ordens, assim como as comunidades terapêuticas de diversas orientações religiosas ou sem orientação religiosa alguma, utilizam estas prerrogativas na condução do tratamento dos usuários de drogas e na definição de seus projetos terapêuticos como veremos mais adiante. Poucas décadas após a fundação da organização, o AA já estava articulado com outras instituições.

Os alcoólicos chegavam em grande número a Akron para obter cuidados médicos no Hospital Saint Thomas, uma instituição administrada pela Igreja Católica. O Dr. Bob se integrou ao corpo médico desse hospital e ele e a irmã Ignatia, também do pessoal do hospital, prestaram cuidados médicos e indicaram o programa a cerca de 5.000 alcoólicos internados. Após a morte do Dr. Bob, em 1950, a irmã Ignatia seguiu trabalhando no Hospital da Caridade, em Cleveland, onde contava com a ajuda dos Grupos de AA locais e onde outros 10.000 alcoólicos internados encontraram Alcoólicos Anônimos pela primeira vez. 
Esse trabalho foi um grande exemplo de boa vontade, que permitiu comprovar que AA cooperava eficazmente com a medicina e a religião (Alcoólicos Anônimos, 2012).

Em 1953, um grupo de pessoas que fazia parte dos Alcoólicos Anônimos decidiu morar junto a fim de manterem-se em abstinência. Eles fundaram a Comunidade Terapêutica Synanom, na Califórnia (EUA). A partir desta iniciativa, foram surgindo outras comunidades terapêuticas que seguiam o mesmo modo de funcionamento da precursora Synanom. No Brasil, as comunidades terapêuticas estão vinculadas, principalmente, às igrejas evangélicas e católicas. Em 1968, na cidade de Goiânia, surge no Brasil a primeira Comunidade Terapêutica denominada Desafio Jovem, oriunda de um movimento religioso evangélico. Em 1978, na cidade de Campinas, foi fundada a Comunidade Terapêutica Senhor Jesus, oriunda de um movimento religioso coordenado pelo Padre Haroldo Rham, missionário americano (Fracasso, 2008).

De acordo com o Glossário de álcool e drogas (Brasília, 2010), as comunidades terapêuticas são caracterizadas por um ambiente estruturado onde os indivíduos com transtornos por uso de substâncias psicoativas residem para alcançar a reabilitação e são, em geral, isolados geograficamente. Elas possuem um modelo residencial: uma vez internado, o "residente" deverá comprometer-se com o programa de tratamento da instituição. Os tratamentos podem durar seis, nove ou doze meses, a critério da própria comunidade terapêutica. Os residentes são mantidos em atividades durante 0 transcorrer do dia, que podem variar entre atividades laborais, terapêuticas e religiosas. As famílias podem realizar visitas à comunidade terapêutica, geralmente, uma vez por mês, em data definida pelo local. Muitas delas exigem que a pessoa que deseja visitar o familiar internado esteja participando de algum grupo como o Amor Exigente ${ }^{1}$, pedindo comprovação da participação no grupo para que a visita seja autorizada (Conselho Federal de Psicologia, 2011).

As comunidades terapêuticas pretendem promover mudanças no comportamento dos indivíduos e favorecer sua reinserção na sociedade. Para que isso aconteça, valores como espiritualidade, responsabilidade, solidariedade, amor e honestidade são criados. As comunidades terapêuticas possuem um modelo residencial e seu funcionamento está pautado na premissa de que, diante da impossibilidade de promover mudanças no indivíduo 'dependente químico', é necessário alterar o meio onde ele vive e o retirar da situação em que acontece $o$ consumo de drogas. $O$ processo terapêutico preconiza intervenções individuais e sociais com atribuição de funções, direitos e responsabilidades ao 'indivíduo 
dependente químico', em um ambiente livre de substâncias psicoativas (Sabino \& Cazenave, 2005).

A partir de tal descrição das comunidades terapêuticas, podemos relacionar esse modelo com o manicômio. O surgimento destas instituições, embasado na compreensão de que a exclusão dos loucos estava justificada pela necessidade de um local 'protegido', com regramentos de horário na rotina dos asilados, foi por séculos justificado pelas ciências como possibilidade única para os portadores de transtornos mentais.

Raupp \& Milnitiski-Sapiro (2008), descreve que o modelo moral que embasa 0 tratamento na comunidade terapêutica dificulta 0 desenvolvimento das singularidades e potencialidades dos internos, 0 que também dificulta o alcance de uma recuperação duradoura. Nas comunidades terapêuticas pesquisadas por esta autora, não havia distinção entre uso, abuso e dependência de substâncias psicoativas, sendo o mesmo programa terapêutico aplicado a todos os residentes das instituições.

No que diz respeito à religião, a moral cristã imposta como cerne do tratamento configura-se como doutrinação, uma vez que a questão religiosa não é uma resposta adequada às necessidades dos residentes na instituição. Tal imposição acaba limitando o desenvolvimento de recursos para que outras opções de vida possam ser feitas para além da questão religiosa. Sendo assim, o estilo de vida preconizado pela comunidade terapêutica fornece modelos muito rígidos para as características do mundo contemporâneo (Raupp \& Milnitiski-Sapiro, 2008).

\section{A articulação entre moral religiosa, disciplina e biopolítica no modelo das comunidades terapêuticas}

Foucault (2010a) coloca que a psiquiatria funciona equacionando a vinculação de todo o diagnóstico de loucura à eminência de um perigo. Assim, ela se justifica como uma intervenção autoritária na sociedade, apoiada em um saber científico, funcionando como poder e ciência da higiene pública, pois demonstra ser capaz de perceber perigos onde ninguém ainda pode ver e se pode percebê-lo, é por que se sustenta em um saber médico. Então, o poder psiquiátrico desloca-se, deixando de inferir sobre o pensamento doente, sobre a capacidade de compreensão do doente, sobre o querer consciente do doente, para investir sobre o que o doente faz, o que ele é capaz de cometer. Para que a psiquiatria pudesse constituir-se e instaurar-se como poder e saber de proteção social, o primeiro interesse de seu investimento se deu pela loucura que mata.

As pequenas irregularidades de conduta, que não pertencem, especificamente, à loucura, puderam ser trazidas para o domínio da 
psiquiatria através do aparecimento da noção de instinto. É com essa noção que torna-se organizar a problemática do anormal na esfera das condutas cotidianas. A função do instinto dentro do jogo de saber-poder é a capacidade de transformar, do ponto de vista da ciência, a ausência de razão de um ato em um mecanismo patológico positivo. No lugar do antigo domínio do delírio e da demência, o instinto é que passa a ocupar um lugar central na psiquiatria (Foucault, 2010a).

Sendo assim, o uso de drogas pode ser entendido sob a luz da ausência do controle dos instintos e da ausência de razão. Assim, podemos então dizer que aquele que usa drogas perde o controle de si mesmo e age movido por seus instintos, podendo colocar outras pessoas em risco, além de si mesmo. Com base nesse entendimento, o usuário de drogas pode ser tomado como objeto de intervenção da psiquiatria, devendo ser normalizado. A normalização do usuário de drogas tem sido apresentada, especialmente, pela disseminação das instituições denominadas comunidades terapêuticas, que se propõem a produzir sujeitos abstêmios das substâncias psicoativas.

Nesse entendimento, os usuários de drogas parecem estar tomados por essa operação da psiquiatria. Diante do uso de substâncias psicoativas, o sujeito usuário de drogas tem seus instintos influenciados por substâncias "desconhecidas". A abstinência, para aqueles que são considerados dependentes químicos, também pode desencadear instintos que colocam a sociedade e a própria família do usuário em risco: roubar, seja de estranhos ou de sua própria casa, para comprar drogas. Atos esses que são justificados pelos 'maus' instintos provocados pelo uso de drogas. Nesta compreensão, é a falta de controle desses instintos e o perigo que estes oferecem à sociedade e ao 'bom' funcionamento familiar que sustentam a defesa de instituições com funcionamento residencial, de caráter fechado, como as comunidades terapêuticas, estarem vinculadas à rede de saúde pública.

As comunidades terapêuticas, por serem instituições fechadas, designadas a dispensar tratamento para usuários através da segregação social, com normas rígidas de funcionamento e controle sobre a vida dos indivíduos, remetem à memória de antigas instituições, como o leprosário e o manicômio. Essas, presentes no mundo ocidental desde a Idade Média, parecem reeditar-se em instituições que, ainda hoje, estão presentes nas diversas sociedades. As comunidades terapêuticas, assim, parecem ser como reedição deste modelo, agora sob a justificativa da dependência química como a doença que deve ser tratada através do isolamento. As práticas destas instituições, desde a Idade Média com as dos leprosários e hospícios, constituíram modos de tratamento e sujeitos, que alicerçou saberes que a Reforma Psiquiátrica contestou, mas que ainda 
encontram condição de existência por estarem arraigados aos saberes de disciplinas como a medicina, a psicologia, e o direito.

Nas primeiras páginas do livro História da Loucura, Foucault (1999) faz um grande apanhado histórico a respeito da lepra na Europa no final da Idade Média. A partir desse período, a lepra começa a desaparecer, muito mais em função das práticas segregadoras do que de intervenções da medicina. Com o fim da epidemia da lepra, os leprosários que serviram de grandes depósitos dos doentes, ficam sem utilidade. $O$ que permanece, apesar dos leprosários encontrarem-se vazios, é o sentido de exclusão deste personagem do leproso. O leproso é excluído da sociedade, mas sua existência é relacionada à uma manifestação de Deus. É através dessa exclusão que o leproso obterá sua salvação. O leproso está excluído da Igreja, porém não está excluído das graças de Deus (Foucault, 1999).

A exclusão da lepra comportava uma rigorosa divisão que não permitia o contato entre um indivíduo leproso com os demais indivíduos e que o colocava fora dos muros da cidade e fora dos limites da comunidade. Esses indivíduos excluídos eram desqualificados jurídica e politicamente. A exclusão dos leprosos era acompanhada de uma cerimônia fúnebre, eles eram declarados mortos e, nesse momento, seus bens passavam a ser transmissíveis a outros proprietários (Foucault, 2010a).

Contudo, apesar do desaparecimento da lepra, essas estruturas segregadoras permanecerão e, nos antigos leprosários, os jogos de exclusão serão reeditados com os pobres, os vagabundos, os presidiários, os alienados. Esses são os personagens que foram colocados no lugar que antes era ocupado pelo leproso e, novamente, essa exclusão pretende uma salvação. Em uma cultura diferente, este modelo de exclusão subsistirá sob a forma de exclusão social, todavia de reintegração espiritual (Foucault, 1999).

O modelo de tratamento dos leprosários e dos manicômios conforma uma lógica de segregação dos doentes ainda presente no contemporâneo. Mesmo dentro do modelo de tratamento proposto pela Reforma Psiquiátrica, encontramos grupos terapêuticos para pessoas com uma patologia específica. Temos uma "ordem" estabelecida de tratar o diagnóstico e não o sujeito em sua singularidade transcendendo esta racionalidade segregadora. A prática dos leprosários e dos manicômios são instâncias que colaboraram para a produção do cuidado sob a forma do internamento e para a produção de sujeitos objetivados por este modelo.

Os espaços fechados de tratamento para pessoas com problemas com o uso de drogas como as comunidades terapêuticas podem ser consideradas como espaços onde se estabelecem relações de dominação daquele que exerce um poder dito terapêutico sobre um sujeito desprovido de seus direitos, "[...] abandonado à 
arbitrariedade institucional" (Alarcon, Belmonte, \& Jorge, 2012, p.73). A institucionalização é o artifício para práticas desumanizadas, tornando-os sujeitos desprezíveis. Por isso, as críticas feitas aos leprosários e depois aos hospitais psiquiátricos podem se estender à instituições como as comunidades terapêuticas que nasceram à sombra da racionalidade manicomial, pois entendem saúde pela simplificação unicausal e institucionalizam o sujeito (Alarcon et al., 2012).

A construção de políticas de saúde para usuários de drogas centradas no hospital psiquiátrico demarca a interferência significativa do Direito Penal sobre os procedimentos clínicos, assim como a aproximação entre práticas jurídicas e práticas médicas. É dentro deste jogo de poder que o usuário de drogas se vê ora perante 0 poder da criminologia, ora diante do poder da psiquiatria, ora encarcerado na prisão, ora internado no hospício. Esse conjunto institucional está voltado para o indivíduo que não é nem exatamente doente nem propriamente criminoso, mas sim para o indivíduo, eventualmente, perigoso, nesse caso, os usuários de drogas (Foucault 2010a).

Porém, atualmente, não é só dentro das prisões e dos hospícios que os usuários de drogas estão confinados. As Comunidades Terapêuticas e Fazendas Terapêuticas trazem, além da disciplina, outro elemento que a complementa: a moral religiosa (Passos \& Souza, 2011).

A justiça, a psiquiatria e a moral cristã compõem uma rede de instituições que tem como objetivo comum e único a abstinência, ou seja, a conformação de sujeitos que não tenham problema com o uso de drogas. Sujeitos esses que possam estar inseridos social e economicamente, fazendo 'girar a roda' de produção e consumo de nossa sociedade. A moral religiosa associa o prazer ao mal - associa o prazer da carne ao uso de drogas, que, historicamente, é objeto de intervenção do poder pastoral, que, atualmente, se alia ao poder disciplinar. A problematização moral do uso de drogas assenta-se sobre um conjunto de regras morais cristã, que situou o prazer sob o signo do mal e da morte (Passos \& Souza, 2011).

Siqueira (2010), afirma que existem três espaços destinados aos usuários de drogas, que são: cadeia, igreja e hospitais psiquiátricos. Lugares escolhidos a fim de desempenharem a função de 'controle da sociedade' por meio de leis que estão pautadas nos princípios morais. Assim, há uma produção de sujeitos com identidades padronizadas em que a singularidade e as diferenças não são respeitadas. Esses espaços oferecem a garantia de manutenção da invisibilidade dessas diferenças. As comunidades terapêuticas, em sua estrutura e funcionamento, organizam-se e articulam-se como cadeia, igreja e hospital psiquiátrico. As comunidades terapêuticas não podem ser caracterizadas unicamente nem como cadeia, nem como igreja, nem 
como hospital psiquiátrico, mas, justamente, é na articulação do funcionamento destas três instituições que elas encontram sua especificidade - que mais se aproxima dessas três instituições do que dos serviços que preconizam os princípios do SUS. Na cadeia, temos, principalmente, o caráter fechado, a impossibilidade do indivíduo preso circular na cidade, além do sentido de que o encarceramento é uma medida necessária para aquele que comete um crime. No caso dos usuários de drogas, seu crime (que, nesse caso, é moral) foi justamente o uso de substâncias ilícitas, que, portanto, será combatido com o encarceramento em um local para o tratamento da drogadição, a fim de devolver para a sociedade, um indivíduo abstêmio que consiga se inserir à lógica da moral. $O$ método utilizado para recuperar moralmente este indivíduo para torná-lo produtivo se dá, principalmente, pela questão religiosa. É neste ponto que vemos como a comunidade terapêutica toma as características de instituição religiosa. A 'espiritualidade' é colocada como um dos pilares para o tratamento nas comunidades terapêuticas. Atividades que envolvem a leitura da bíblia e a prática de orações são rotineiras nessas instituições. Essas práticas configuram, o caráter confessional impondo a responsabilização individual a causa e consequência de seus atos, no caso do uso de drogas.

Desta forma, as comunidades terapêuticas em sua natureza social que segue a lógica do internamento são uma das tantas formas históricas contemporâneas do jogo de exclusão dos seres humanos, em que eclodem rituais de segregação e purificação por meio das práticas terapêuticas e dos discursos morais. As comunidades terapêuticas possuem um "híbrido" de concepções morais e éticas, conjugando "velhas" e "novas" visões e valores acerca do indivíduo e da sociedade (Valderrutén, 2008).

\section{Projetos terapêuticos de atenção aos usuários de álcool e outras drogas das comunidades terapêuticas: a análise de quatro propostas de tratamento}

A fim de visibilizar como as comunidades terapêuticas se organizam para receber e tratar os usuários de substâncias psicoativas, através de pactuação com a atual política de drogas no país, apresentaremos projetos de quatro comunidades terapêuticas. Dessa forma, apontaremos como se constitui o entrelaçamento entre o caráter religioso e disciplinar dessas instituições a partir do conteúdo disponível em suas páginas na internet. Com a análise da proposta terapêutica dessas comunidades, pretendemos discutir os efeitos do entrelaçamento religioso-disciplinar nos modos de subjetivação do sujeito usuário de drogas. São elas: Comunidade Terapêutica Fazenda Renascer (Novo Hamburgo/RS), Centro de Reintegração 
Social Aprendendo a Viver (Sapiranga/RS), Comunidade Terapêutica Ferrabraz (Sapiranga/RS) e Fazenda do Senhor Jesus (Viamão/RS). Todas possuem página na internet ${ }^{2}$ e disponibilizam, publicamente, os projetos terapêuticos de tratamento para usuários de drogas bem como demais informações sobre a estrutura institucional e seu funcionamento. A escolha por estas quatro comunidades terapêuticas deu-se pela riqueza e detalhamento das informações contidas em seus sítios.

A Comunidade Terapêutica Fazenda Renascer é direcionada para pessoas do sexo masculino na faixa dos 16 aos 60 anos, tendo capacidade para 60 residentes na instituição. Sua filosofia de trabalho está baseada em uma declaração feita pelo jornalista Richard Beauvais após sua internação na Comunidade Terapêutica Daytop Village nos EUA, que segue a premissa dos Alcoólicos Anônimos.

A linha mestra do tratamento na Fazenda Renascer são os Doze Passos de Recuperação do AA. O programa terapêutico está estruturado em três princípios básicos: espiritualidade, disciplina e trabalho e possui um cronograma para um ano de tratamento. A disciplina é promovida como um meio para dominar os impulsos, uma vez que, no entendimento da comunidade terapêutica, o dependente químico tem aversão à regras e normas e, por isso, foge dos padrões estabelecidos pela sociedade. Portanto, a comunidade terapêutica tem a pretensão de produzir sujeitos aptos aos padrões sociais, que insiram normativamente aos ditames da sociedade. O público da comunidade terapêutica são os sujeitos "desajustados".

Essa instituição considera que a dependência química é uma doença biopsicossocial e espiritual e, por esse motivo, o usuário de drogas precisa de ajuda externa para redirecionar sua vida, promovendo uma transformação através da mudança de seus valores e do seu estilo de vida. Em outros termos, no tratamento da comunidade terapêutica, opera-se uma constituição de novos valores através de práticas ditas "espirituais" e, portanto, valores advindos de preceitos religiosos. Não há informações sobre quais profissionais atuam no local, mas são citados os seguintes recursos de tratamento: assistência psicológica (individual e em grupo), esporte e lazer, educação física, tai chi chuan, karatê, academia e prática de informática.

O Centro de Reintegração Social Aprendendo a Viver está localizado em um centro urbano, seguindo o modelo residencial. A instituição refere que o tratamento é personalizado, sem crédulo religioso, mas espiritual, e destaca que não tem "trabalhos forçados". O tratamento está dividido em três etapas: desintoxicação, tratamento de dependência química e pós-tratamento. A desintoxicação é feita em observação constante por um técnico de enfermagem, com verificação de sinais e dispensação de medicação, conforme prescrição médica. Na segunda etapa, o residente deve identificar sua 
doença, aceitar sua condição de pessoa doente que necessita de tratamento, formular uma programação pessoal de reabilitação, conhecer o programa de doze passos do AA e preparar-se para a sua reinserção social. Ainda que essa comunidade terapêutica afirme não ter crédulo religioso, ao impor o programa dos doze passos do AA, fica subentendido que o usuário deva, no mínimo, acreditar em um "deus" ou em um "poder superior". Com isso, podemos inferir que há uma conformação 'espiritual' no tratamento, uma vez que, para tomar o método do AA como diretriz, o sujeito deve reconhecer como verdade as premissas dos doze passos.

O pós-tratamento consiste em acompanhamento ambulatorial e participação em reuniões semanais de grupos de AA ou NA. O Centro possui uma equipe técnica formada por médico psiquiatra, médico clínico geral, psicóloga, assistente social e técnicos de enfermagem e oferece como atividades: terapia individual, terapia em grupo, terapia familiar, atendimento psiquiátrico, clínico e psicológico, oficinas terapêuticas, espiritualidade, atividades lúdicas e de lazer, grupos de AA e NA. Assim como na comunidade terapêutica Fazenda Renascer, a instituição também estabelece intervenções sob corpo e "alma" e coloca a espiritualidade como atividade. Portanto, espiritualidade como atividade, como técnica aplicada aos sujeitos, como tratamento. Gros (2008) explica que os exercícios cristãos de confissão e outras práticas de direção configuram a abnegação e a renúncia do sujeito a si mesmo, quando esse de coloca como objeto e, objetivando-se, morre para si mesmo.

A Comunidade Terapêutica Ferrabraz tem seu tratamento baseado na programação dos Doze Passos do $A A$, empregando métodos que decorrem da postura filosófica que têm como base o tripé: oração, trabalho e disciplina. A oração diz respeito ao desenvolvimento da espiritualidade, que é considerada o alicerce fundamental para a recuperação. $O$ trabalho compreende as atividades de manutenção e funcionamento da instituição, resgatando o sentido e o gosto pelo trabalho. A disciplina está associada ao cumprimento rigoroso dos horários, compromissos, apresentação pessoal, tarefas, comunicação adequada e vocabulário. Dentre as três premissas de tratamento, a oração e o desenvolvimento da espiritualidade são considerados o alicerce para o tratamento. $O$ desenvolvimento da espiritualidade diz respeito à construção de valores de ordem religiosa, inexistentes antes da internação, e que, sendo instituídos pelos sujeitos, os modificam, para assim obterem a recuperação.

O funcionamento da instituição Ferrabraz dá-se em sistema aberto com regime de residência em ambiente protegido. Baseados em Kurt Lewin (sem citar nenhuma obra ou referência bibliográfica), a comunidade terapêutica afirma que o dependente químico só tem condições de se manter abstêmio após um período de tempo considerável afastado de seu meio original. O programa de 
tratamento é desenvolvido em nove meses consecutivos, divididos em três etapas. A primeira etapa é a adaptação e desintoxicação, que acontece no primeiro trimestre da internação. A segunda etapa, no segundo trimestre, é a conscientização e a última etapa é caracterizada pela ressocialização. Na última fase, são permitidas visitas às famílias que duram uma semana. A instituição oferece atendimento com psicólogos, assistentes sociais e psiquiatras. A metodologia empregada consiste em diversas técnicas terapêuticas grupais: grupo dos doze passos dos Alcoólicos Anônimos, grupo de amor exigente, grupo de sentimento, grupo de auto-ajuda, grupo de socioterapia, grupo de espiritualidade, grupo de laborterapia, grupo psicológico, grupo de terapia racional emotiva. Técnicas conformadas por um caráter confessional, em que o sujeito deve dizer tudo de si e sobre si para alcançar os objetivos terapêuticos da instituição, pautadas pelos conhecimentos da psicologia e das práticas cristãs.

A Comunidade Terapêutica Fazenda do Senhor Jesus tem seu funcionamento estruturado a partir de valores físicos, éticos, morais, intelectuais e espirituais e entende que os valores de uma comunidade terapêutica estão para ela assim como sangue está para a vida. Os valores estão designados conforme os princípios fundamentais do código de ética da Federação Brasileira de Comunidades Terapêuticas (FEBRACT) e são definidos como: respeito à dignidade humana; permanência e aceitação do programa de forma livre e voluntária; permanência assegurada em ambiente livre de drogas, sexo e violência; amor responsável; honestidade; solidariedade; busca de um sentido de vida.

A instituição determina um tratamento com duração de 9 meses e seu público é composto por pessoas do sexo masculino. Existem cerca de 96 vagas na comunidade terapêutica. Para o ingresso, é necessário que a pessoa se submeta a um processo de triagem e avaliação. Neste processo, inclui-se avaliação psicológica e avaliação socioeconômica, com a necessidade de acompanhamento de um responsável pela internação. A equipe de trabalho é formada por dependentes químicos em recuperação com estágio em comunidade terapêutica. Com isso, a instituição visa a articulação entre a experiência de vida dos dependentes químicos com a capacitação técnica de profissionais, que são voluntários, da área da toxicologia, psicologia, assistência social, saúde e administração. No que concerne às atividades terapêuticas, a comunidade terapêutica conta com: laborterapia, exercício de rígida disciplina individual e coletiva, desenvolvimento de vida comunitária, estudo e vivência dos doze passos do $A A$, estudo e vivência dos doze princípios do Amor Exigente, reuniões de grupo com várias destinações, atividades esportivas e lúdicas e oração sob todas as formas.

A conformação de projetos terapêuticos para o tratamento pelo viés da disciplina, da espiritualidade e do trabalho operam sobre os 
sujeitos através de técnicas de cuidado de si, de práticas confessionais aliançadas com os saberes da psicologia e do cristianismo valendo-se do mecanismo da punição para conseguir as metas do tratamento. Três eixos norteadores para a constituição de sujeitos socialmente ajustados, inseridos moralmente na instituição religiosa, no mercado de produção-consumo, nas instituições de ensino, na vida política-econômica. Eixos que com caráter punitivo, delegam os sujeitos a falarem dos seus 'erros' materializados no consumo de drogas; sob pena de práticas físicas para a regulação e a constituição da volta um corpo saudável, produtivo, abstêmio através da metodologia dos doze passos prescritos como:

Os Doze Passos:

1. Admitimos que éramos impotentes perante o álcool - que tínhamos perdido o domínio sobre nossas vidas;

2. Viemos a acreditar que um Poder Superior a nós mesmos poderia devolver-nos à sanidade;

3. Decidimos entregar nossa vontade e nossa vida aos cuidados de Deus, na forma em que O concebíamos;

4. Fizemos minucioso e destemido inventário moral de nós mesmos;

5. Admitimos, perante Deus, perante nós mesmos e perante outro ser humano, a natureza exata de nossas falhas;

6. Prontificamo-nos inteiramente a deixar que Deus removesse todos esses defeitos de caráter;

7. Humildemente rogamos a Ele que nos livrasse de nossas imperfeições;

8. Fizemos uma relação de todas as pessoas que tínhamos prejudicado e nos dispusemos a reparar os danos a elas causados;

9. Fizemos reparações diretas dos danos causados a tais pessoas, sempre que possível, salvo quando fazê-lo significasse prejudicá-las ou a outrem;

10. Continuamos fazendo o inventário pessoal e, quando estávamos errados, nós o admitíamos prontamente;

11. Procuramos, através da prece e da meditação, melhorar nosso contato consciente com Deus, na forma em que $O$ concebíamos, rogando apenas o conhecimento de Sua vontade em relação a nós e forças para realizar essa vontade;

12. Tendo experimentado um despertar espiritual, graças a esses Passos, procuramos transmitir esta mensagem aos alcoólicos e praticar estes princípios em todas as nossas atividades (Revista Vivência, 2011, p. 1). 


\section{Práticas confessionais: a conformação dos sujeitos nas comunidades terapêuticas}

Para entender como se estabeleceram as práticas de confissão, utilizaremos os ensinamentos de Foucault (1988, 2006, 2010a, 2010b) sobre esta prática. De acordo com Foucault (2010a), a revelação forçada é um procedimento de poder fundamental. No interior dos procedimentos de individualização pelo poder, conforme Foucault (1988), temos a inscrição da confissão da verdade. O autor demonstra através de seus estudos sobre a sexualidade, a institucionalização de diversos procedimentos de revelação desse enunciado, como a psiquiatria, a psicanálise e a sexologia. O fio condutor desta institucionalização foi o ritual de penitência.

Originalmente, o ritual de penitência não incluía a revelação obrigatória. A absolvição dos pecados dava-se, exclusivamente, pelas penas que o individuo se infligia, adotando o estatuto de penitente. Somente bispo tinha o direito de designar o estatuto de penitente à alguém e isso só poderia acontecer uma vez na vida daquele que solicitava esse estatuto. A partir do século VI, esta penitência assume um novo modelo e passa a ser a penitência tarifada - seguindo um modelo laico, judiciário e penal. Daí surge a obrigatoriedade da revelação ao padre, já que ele que indicaria qual penitência deveria ser consumada para que o pecado pudesse ser remitido. Pouco a pouco, o ritual da penitência foi se deslocando para formas simbólicas, estreitando-se cada vez mais em torno da própria revelação (Foucault, 2010b).

$\mathrm{Na}$ direção cristã, três elementos são fundamentais: o princípio da obediência sem fim, o princípio do exame incessante e o princípio de confissão exaustiva. Na direção de consciência, não existe coerção. 0 dirigido quer sempre ser dirigido. Existe um laço de inteira liberdade de aceitação da direção. Na direção, existem técnicas que são meios de vincular uma vontade a outra. A verdadeira relação de direção fixa por fim a perfeição, a tranquilidade da alma, a ausência de paixões, a maestria de si, ou seja, uma relação de si consigo. O dirigido busca, então, uma finalidade que não é externa, mas uma finalidade interna que pode ser entendida como um modo de relação de si consigo (Foucault, 2010b).

Por consequência, se chamarmos subjetivação à formação de uma relação definida de si consigo, pode-se dizer que a direção é uma técnica que consiste em ligar duas vontades de maneira que elas restem uma em relação a outra continuamente livres; de as ligarem de tal maneira que uma queira isso que quer a outra, mas isso com uma finalidade de subjetivação, que quer dizer, de acesso a uma certa de relação de si consigo (Foucault, 2010b, p. 90). 
Foucault (2006) coloca que a prática do interrogatório e da extorsão da confissão nunca mudou no interior da psiquiatria, constituindo-se como um procedimento constante. O interrogatório é uma forma de fixar o indivíduo, de vincular o indivíduo a sua identidade social. Portanto "o interrogatório é um método disciplinar e, nesse nível, podem-se efetivamente identificar seus efeitos" (Foucault, 2006, p. 300). O interrogatório é um dos "elementos de fratura do sistema disciplinar", pois marca o momento em que o saber da medicina passa a falar não em termos de poder, mas em termos de verdade. Temos uma tecnologia da verdade que se afina com a prática científica.

A confissão é um ato de verdade em que o sujeito é ator, porque a verdade surge através do discurso que traz à tona aquilo que estava na obscuridade. O sujeito também é testemunha, uma vez que ele afirma que isso se passou em sua consciência, em uma observação interior sobre si mesmo. Ainda, esse sujeito é objeto, pois ele é quem está na cena de seu testemunho e na manifestação da verdade que ele opera (Foucault, 2010b).

Os passos número 1 (Admitimos que éramos impotentes perante 0 álcool - que tínhamos perdido o domínio sobre nossas vidas) e 5 (Admitimos perante Deus, perante nós mesmos e perante outro ser humano, a natureza exata de nossas falhas) convocam o sujeito a admitir para si e para os outros sua impotência, sua falta de autocontrole, seu erro ao consumir álcool. Nos itens 4 (Fizemos minucioso e destemido inventário moral de nós mesmos) e 10 (Continuamos fazendo o inventário pessoal e, quando estávamos errados, nós o admitíamos prontamente), a orientação é para que o sujeito faça seu próprio inventário moral, seu exame de consciência e continue sempre o fazendo, a fim de manter a auto-vigilância sobre suas condutas e revelar aos outros suas falhas quando acontece 0 descumprimento do que está prescrito. Nesses quatro passos, vemos como o caráter da confissão, da revelação forçada, se apresenta como técnica disciplinar na metodologia dos doze passos.

A partir do século XII a confissão passa a ser obrigatória (anual para leigos, mensal ou semanal para clérigos). Com essa obrigatoriedade, passa a existir a obrigação de regularidade, de continuidade e de exaustividade (já que todos os pecados deviam ser revelados para serem inquiridos pelo padre) na confissão. A obrigação da penitência estende-se para a obrigação da confissão sacramental que tem seu desdobramento na revelação das faltas propriamente ditas (Foucault 2010b).

A revelação contínua e exaustiva pode ser visibilizada nos passos 4 e 10 , já que o passo 10 é praticamente a reedição do que já havia sido indicado pelo passo 4 . O passo 10 é um segundo aviso que reforça a necessidade de confissão, que engendra e constitui o modo como o 
sujeito usuário de drogas deve falar de si (como sujeito que falha, que erra, como um "drogado") e a obrigatoriedade de falar si na comunidade terapêutica e por toda a vida, para manter-se em abstinência. A abstinência dos sujeitos apresenta-se, então, como o grande objetivo das comunidades terapêuticas, forjando uma população de sujeitos com o comportamento que possibilite que eles sejam produtivos economicamente.

O exame de consciência, esse exame de si mesmo como princípio da direção cristã, consiste em uma atividade que se exerce sobre o fluxo do pensamento em sua atualidade, apreendendo o pensamento no momento que ele pensa. É no exame de si mesmo que se obtêm as certezas fundamentais da consciência, é onde se deve procurar uma relação fundamental com a verdade. A obrigação da confissão está tão arraigada em nós mesmos que não é percebida como um efeito do poder coercitivo. Assim, "a confissão é um ritual de discurso onde o sujeito que fala coincide com o sujeito do enunciado" (Foucault, 2006, p. 70). Os passos 1 e 5 ventilam, exatamente, o postulado do exame de consciência, da busca da verdade 'dentro de $\mathrm{si}^{\prime}$ ', da verdade sobre o uso de drogas, sobre o mal que elas causaram, sobre o erro que elas representam, sobre sua fraqueza, sobre sua vitimização diante da substância que Ihe corrompeu. Essa é verdade que subjetiva o usuário de drogas em tratamento nas comunidades terapêuticas e é verdade tomada pela política pública sobre drogas em vigência no Brasil.

\section{Considerações finais}

Se, com o desenvolvimento de seu estudo sobre a sexualidade, Foucault (1988) demonstrou existir um discurso proliferante que remetia o individuo a este enunciado da sexualidade e, sendo assim, havia o que revelar ao psicanalista, ao psiquiatra, ao sexólogo, talvez seja possível pensar o mesmo sobre a questão das drogas no contemporâneo. As campanhas proibicionistas e preventivas ao uso de drogas que foram veiculadas, veementemente, pela mídia, hoje se apresentam de forma dissipada. Em resposta às campanhas midiáticas, muitos outros discursos emergiram ou voltaram à cena e instauraram-se nas instituições de ensino, nas políticas e nos serviços de saúde, nas leis de trânsito, nos locais de lazer, no andar da vida como um todo da população. Entrelaçado a esse discurso proliferante sobre a droga, vem a necessidade de "tratar" aqueles que têm problemas com o uso delas. Tratamento que é pensado, produzido e protagonizado, essencialmente, pelas disciplinas "psi", por técnicas de disciplinamento e de confissão, que tomam materialidade na prescrição dos passos analisados neste artigo. 
A prática confessional em seu âmbito originário pertencente ao cristianismo, prestava-se ao governo das almas - ao poder pastoral. A confissão, como Foucault demonstrou, foi estendendo-se, reeditando-se, tomando outras frentes, atravessando outros saberes, submergindo em outras disciplinas e, assim, cristalizou-se como prática vigente das disciplinas "psi" especificamente e das disciplinas da área da saúde em geral. Com isso, é possível visibilizar como se estabelece o enlace entre as práticas espirituais das comunidades terapêuticas através dos doze passos e as práticas da psicologia e da medicina, pois o caráter confessional de todas as instâncias citadas ecoam entre si quase que de forma uníssona.

\section{Referências}

Alarcon, S. Belmonte, P. R. Jorge, M. A. S. (2012). O campo de atenção ao dependente químico. In Alarcon S., \& Jorge, M. A. S. Jorge (Orgs). Álcool e outras drogas: diálogos sobre um malestar contemporâneo. (pp.63-82). Rio de Janeiro: Fiocruz.

Alcoólicos Anônimos (2012). Recuperado em 14 junho, 2012, de www.alcoolicosanonimos.org.br

Brasília: Secretaria Nacional de Políticas sobre Drogas (2010). Glossário de álcool e drogas. Recuperado em 18 novembro, 2014, http://www.obid.senad.gov.br/portais/OBID/biblioteca/docume ntos/Publicacoes/cartilhas/328198.pdf

Centro de Reintegração Social Aprendendo a Viver. Recuperado em 15 de março, 2015, de: http://www.aprendendoaviver.com/

Comunidade Terapêutica Ferrabraz. Recuperado em 14 de março, 2015, de http://comunidadeferrabraz.no.comunidades.net/index.php

Conselho Federal de Psicologia (2011). Relatório da $4^{a}$ Inspeção Nacional de Direitos Humanos: locais de internação para usuários de drogas/Conselho Federal de Psicologia. Brasília: Conselho Federal de Psicologia.

Decreto Lei 7179. (2010). Diário Oficial da União (Brasília, DF), 2010. Recuperado em 20 de outubro, 2011, de http://www.planalto.gov.br/ccivil_03/_Ato20072010/2010/Decreto/D7179.htm

Edital no 001/2010/GSIPR/SENAD/MS. (2010) Diário Oficial da União (Brasília, DF). Recuperado em 17 novembro, 2011, de http://portal.saude.gov.br/portal/arquivos/pdf/edital_comu_ter apeuticas.pdf

Fazenda Renascer. Recuperado em 13 de março, 2015, de http://www.fazendarenascer.org.br/ 
Fazenda do Senhor Jesus. Recuperado em 13 de março, 2015, de http://pactopoa.com.br

Foucault, M. (1988). História da Sexualidade I: a vontade de saber. Rio de Janeiro: Graal.

Foucault, M. (1999). História da Loucura (6a ed.). São Paulo: Perspectiva.

Foucault, M. (2006). O poder psiquiátrico: curso dado no Collège de France (1973-1974). São Paulo: Martins Fontes.

Foucault, M. (2010a). Os anormais. São Paulo: WMF Martins Fontes.

Foucault, M. (2010b). Do governo dos vivos: curso no collège de France, 1979-1980: excertos/Michel Foucault. São Paulo: Centro de Cultura Social; Rio de Janeiro: Achiamé.

Fracasso, L. (2008). Comunidade terapêutica: uma abordagem psicossocial. Encontro Interdisciplinar: Dependência Química, Saúde e Responsabilidade Social - Educando e Transformando Através da Educação Física. Recuperado em 14 fevereiro, 2012, de

http://www.fef.unicamp.br/bibli/Encontrointerdisciplinar/Texto $\% 202 \% 20$ Laura.pdf

Garcia, M. L. T., Leal, F. X., \& Abreu, C. C. (2008). A política antidrogas brasileira: velhos dilemas. Psicologia \& Sociedade, $X X(2)$, 267-276. Recuperado em 05 março, 2012, de http://www.scielo.br/scielo.php?script=sci_arttext\&pid=S0102$71822008000200014 \&$ lng $=$ pt\&nrm=iso

Gros, F.(2008). O cuidado de si em Michel Foucault. . In M. Rago, \& A. Veiga-Neto (Orgs). Figuras de Foucault. (pp.127-138, 2. ed. )Belo Horizonte: Autêntica.

Jones, M. (1972). A comunidade terapêutica. Petrópolis: Vozes.

Menezes, M. S. C. (2010). Prevenção com amor exigente: antes que coisas ruins aconteçam. (4a ed.). São Paulo: Loyola.

Medida Provisória 1689. (1998). Diário Oficial da União (Brasília, DF). Recuperado em 15 janeiro, 2012, de http://www.planalto.gov.br/ccivil_03/mpv/Antigas/1689-6.htm

Musumeci, B. (1994). O consumo de álcool no país. In A. Zaluar (Org). Drogas e cidadania: repressão ou redução de riscos. São Paulo: Brasiliense.

Passos, E. H., \& Souza, T. P. (2011). Redução de danos e saúde pública: construções alternativas à política global de "guerra às drogas". Psicologia \& Sociedade, Florianópolis, XXIII(2), 154162. Recuperado em 05 dezembro, 2011, de http://www.scielo.br/scielo.php?script=sci_arttext\&pid=S0102$71822011000100017 \&$ lng $=$ pt\&nrm=iso

Política do Ministério da Saúde para atenção integral a usuários de álcool e outras drogas. (2004). Ministério da Saúde: Brasília: Ministério da Saúde. Recuperado em 10 dezembro, 2011, de 
http://bvsms.saude.gov.br/bvs/publicacoes/pns_alcool_drogas. pdf

Raupp, L. M., \& Milnitiski-Sapiro, C. (2008). A "reeducação" de adolescentes em uma comunidade terapêutica: o tratamento da drogadição em uma instituição religiosa. Psicologia: Teoria e Pesquisa, XXIV(3), 361-368. Recuperado em 15 janeiro, 2012, de

http://www.scielo.br/scielo.php?script=sci_arttext\&pid=S0102$37722008000300013 \&$ lng $=$ en\&nrm =iso

Resolução - RDC no 101. (2001). Diário Oficial da União (Brasília, DF). Recuperado em 10 fevereiro, 2012 de http://www.anvisa.gov.br/legis/resol/101_01rdc.htm

Sabino, N. D. M., \& Cazenave, S. O. (2005). Comunidades terapêuticas como forma de tratamento para a dependência de substâncias psicoativas. Revista Estudos de Psicologia, XXII(2), 167-174. Recuperado em 17 dezembro, 2011, de http://www.scielo.br/scielo.php?script=sci_arttext\&pid=S0103$166 \times 2005000200006 \&$ lng $=$ pt\&nrm =iso

Siqueira, D.(2010). Construindo a descriminalização... In L.M.B., Santos (Org). Outras palavras sobre o cuidado de pessoas que usam drogas. 65-70. Porto Alegre: ideograf/Conselho Regional de Psicologia do Rio Grande do Sul.

Valderrutén, M. del C. C. (2008). Entre "teoterapias" y "laicoterapias": comunidades terapéuticas en Colombia y modelos de sujetos sociales. Psicologia \& Sociedade, $X X(1), 80-$ 90. Recuperado em 17 dezembro, 2011, de http://www.scielo.br/scielo.php?script=sci_arttext\&pid=S010271822008000100009\&lng=pt\&nrm=iso

Vivência. (jan./ fev, 2011). Revista Brasileira de Alcoólicos Anônimos. Ano 26(1), 1-2.

\section{Endereço para correspondência \\ Luciana Barcellos Fossi}

Universidade Federal do Rio Grande do Sul

Programa de Pós-Graduação em Psicologia Social e Institucional

Avenida Ramiro Barcelos, 2777 sala 212, Santana, CEP 90035-003, Porto Alegre RS, Brasil

Endereço eletrônico: lubfossi@hotmail.com

\section{Neuza Maria de Fátima Guareschi}

Universidade Federal do Rio Grande do Sul

Departamento de Psicologia

Avenida Ramiro Barcelos, 2777 sala 212, Santana, CEP 90035-003, Porto Alegre RS, Brasil

Endereço eletrônico: nmguares@gmail.com

Recebido em: 11/06/2014

Reformulado em: 22/09/2014

Aceito em: 13/01/2015 


\section{Notas}

* Mestre pelo Programa de Pós-graduação em Psicologia Social e Institucional da Universidade Federal do Rio Grande do Sul. Especialista em Saúde Coletiva com Ênfase em Gestão e Formação em Saúde Mental pela Escola de Saúde Pública do Rio Grande do Sul. Graduada em Psicologia pela Pontifícia Universidade Católica do Rio Grande do Sul.

** Doutora em Educação pela University of Wisconsin - Madison. Mestre em Psicologia Social e da Personalidade pela Pontifícia Universidade Católica do Rio Grande do Sul. Graduada em Psicologia pela Pontifícia Universidade Católica do Rio Grande do Sul. Professora adjunta da Universidade Federal do Rio Grande do Sul.

1 É caracterizado como uma proposta de qualidade de vida para familiares de usuários de álcool e/ou drogas, orientada por doze princípios, trazida dos EUA pelo Padre Haroldo Rham (Menezes, 2010).

${ }^{2}$ Verificar nas referências bibliográficas. 